\title{
backstory
}

\section{Mapping movements in the deep}

\section{Timm John and colleagues soaked up the beauty, and rain, of Western Norway while attempting to unlock the secrets of deep earthquakes.}

\begin{abstract}
What was the objective of the work?
Understanding the cause of intermediatedepth earthquakes (50-300 $\mathrm{km}$ deep) is a long-standing problem in geology - the high pressures experienced at depth are thought to be incompatible with simple brittle failure, which is known to be the cause of shallow earthquakes. In this study we combined two different approaches, field-based petrology and numerical simulations, to gain insight into the origin and nature of earthquakes that take place at depths of $50 \mathrm{~km}$ and more below the Earth's surface.
\end{abstract}

\section{Why did you choose this particular location for the fieldwork? \\ We chose to carry out the work at the Kråkenes Gabbro in Norway because it is a pristine field location, where it's possible to study the interplay between rock deformation, mineral reactions and aqueous fluid flow in detail. Our initial motivation was the hope that a better understanding of these geological processes would hold the key to understanding intermediate-depth earthquakes; in short, we hoped to find out which of these factors is most important for making intermediate-depth earthquakes possible.}

\section{What sorts of samples were you after?}

We started by collecting detailed field observations (small-scale maps and photographs of the shear zones and earthquake fault zones) in locations where the structures are simple and well-preserved. These initial observations indicated that the field location was characterized by the coexistence of alternating shear zones and earthquake fault zones. We took several rock samples from these areas to verify this idea.

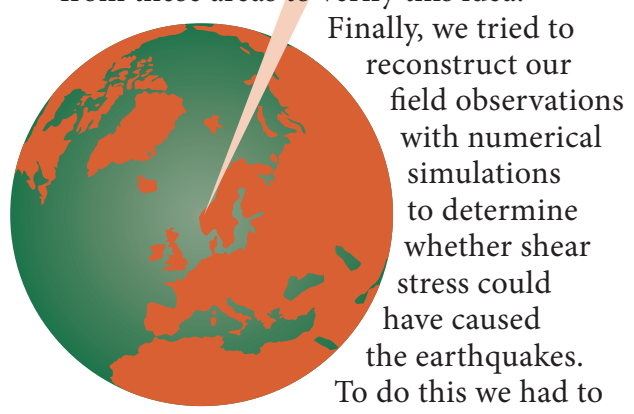

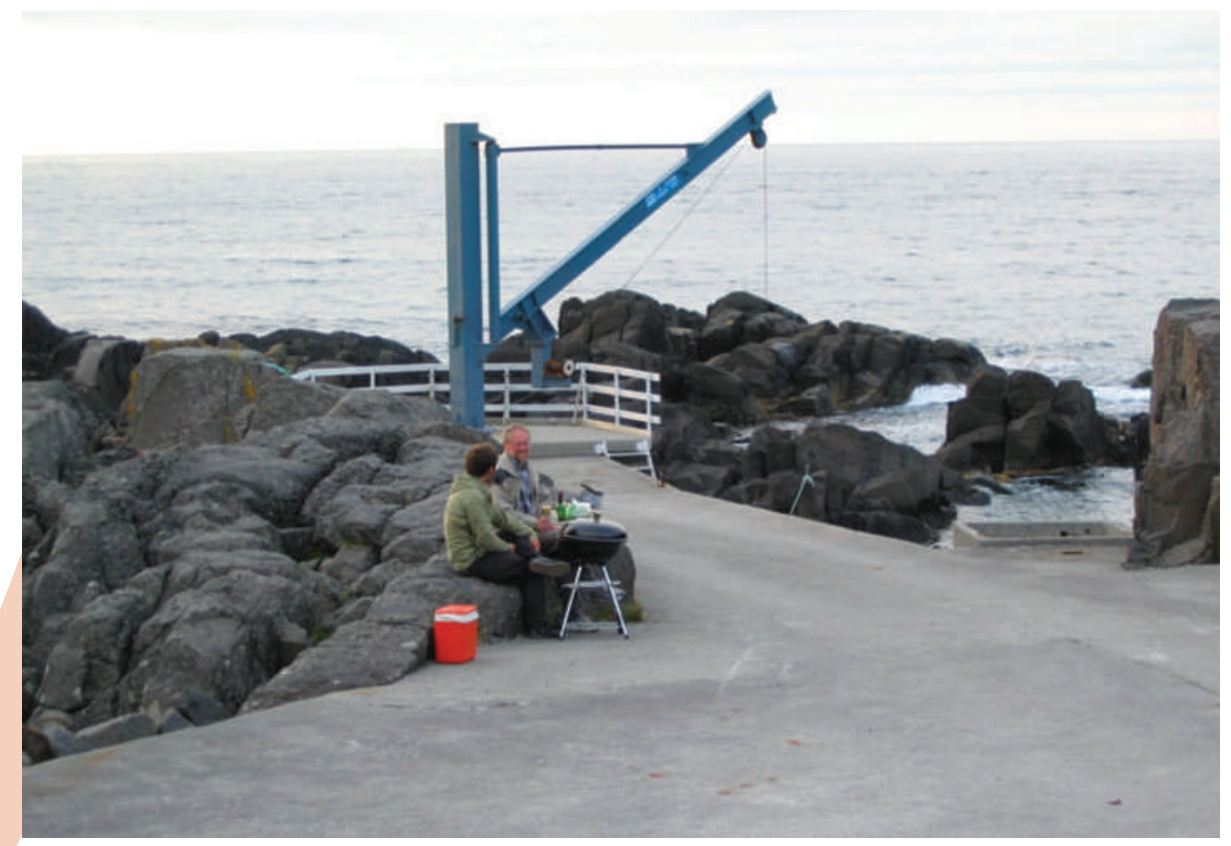

Timm John and Håkon Austrheim take a break from rock sampling.

extract data from our field observations, and feed it into our model.

\section{Did you encounter any difficulties?}

Kråkenes is a wonderfully remote place - a few houses, a small harbour and a beautiful landscape - but, typical of Western Norway, it often rained heavily, so outdoor activities such as detailed mapping and drilling were sometimes impossible. However, the real hurdles emerged when we started to combine the field-based data with physics through numerical simulations. Finding a 'common language' in such an international (two Russians, two Norwegians and two Germans) and interdisciplinary (structural geologists, petrologists and geophysicists) group was an interesting challenge. But, as the modellers went into the field and drilled samples, and the field geologists joined the modellers at their computers, these challenges usually proved to be fun, rather than problematic.

Did you have encounters with dangerous animals?

The only animals we encountered were sheep, together with some seagulls and fish. We were able to deal with all of them: the sheep behaved well, the seagulls made too much noise and the fish were tasty.

\section{What was the highlight of the expedition?}

The beauty of Western Norway, and Kråkenes in particular, is outstanding. Scientifically, we were thrilled with the discovery of alternating shear zones and earthquake fault zones.

\section{Did the trip give you any ideas for future research projects?}

We now want to see how earthquake fault zones and shear zones are related to the hydration patterns we observed at Kråkenes, and determine whether the process that caused earthquakes and shear zone formation also facilitated the infiltration of fluid into this highly impermeable rock.

This is the backstory to the work by Timm John and collegaues, published on page 137 of this issue. 